\title{
Lithium isotopes in exchangeable and silicate fractions of clay sized fluvial sediments along a climatic transect
}

\author{
NESTOR GAVIRIA-LUGO ${ }^{1}$, CHARLOTTE LÄUCHLI ${ }^{2}$, \\ HELLA WITTMANN $^{1}$, ANNE BERNHARDT ${ }^{2}$, DIRK \\ SACHSE $^{1}$ AND PATRICK FRINGS ${ }^{1}$ \\ ${ }^{1}$ GFZ German Research Centre for Geosciences \\ ${ }^{2}$ Free University of Berlin \\ Presenting Author: nestgav@gfz-potsdam.de
}

Silicate weathering is a key process in the regulation of climate over geological timescales, as it is responsible for net carbon removal from the atmosphere. Thus, the study of weathering in sedimentary archives has gained relevance. A promising proxy to unravel the interactions between climate and weathering is lithium isotope ratios $\left({ }^{7} \mathrm{Li} /{ }^{6} \mathrm{Li}\right.$, expressed as $\left.\delta^{7} \mathrm{Li}\right)$, because $\mathrm{Li}$ isotopes are fractionated during formation of clays which preferentially incorporate the lighter isotope $\left({ }^{6} \mathrm{Li}\right)$ into their structure $[1,2,3]$. Additionally, the so-called exchangeable fraction (accessible by chemical extraction) is constituted by $\mathrm{Li}$ adsorbed to the exchange sites of clay minerals, this exchange pool is likely in equilibrium with river waters [4].

Although multiple field studies have demonstrated the potential of $\delta^{7} \mathrm{Li}$ to trace weathering intensity or distinguish weathering regimes $[1,5,6]$, these studies have focused on $\delta^{7} \mathrm{Li}$ in river dissolved Li and/or bulk suspended loads. Secondary clays formed during weathering should be the isotopic counterpart to dissolved $\mathrm{Li}$, but they have received little attention. Even less is known about $\mathrm{Li}$ isotopes in the exchangeable fraction of claysize sediments and how they behave under different weathering conditions.

In this work we analyze $\delta^{7} \mathrm{Li}$ of the exchangeable and residual silicate fractions in clay-sized separates of fluvial sediments from twelve rivers along a transect from $26^{\circ} \mathrm{S}$ to $41^{\circ} \mathrm{S}$ in Chile. The catchments are located along a strong vegetation and precipitation gradient, with precipitation ranging from 25 to 2300 $\mathrm{mm} / \mathrm{yr} . \delta^{7} \mathrm{Li}$ in the exchangeable fraction exhibits a greater range $\left(-16 \%\right.$ to $4 \%$ ) than the silicate fraction $\left(-6 \%\right.$ to $-2 \%$ ). $\delta^{7} \mathrm{Li}$ from the silicate fraction presents a negative correlation with mean annual precipitation rates in the catchments, while $\delta^{7} \mathrm{Li}$ from the exchangeable fraction shows no clear correlation with climatic parameters. These results provide new insights into the effects of climate on the lithium isotope fractionation during clay formation.

[1] Pistiner \& Henderson (2003), EPSL, 214 (1-2), 327-339. [2] Vigier, et al. (2008), GCA, 72 (3), 780-792. [3] Hindshaw, et al. (2019), GCA 250, 219-237. [4] Tipper, et al. (2021), PNAS 118(1). [5] Dellinger, et al. (2014), EPSL 401, 359-372. [6] Millot, et al. (2010) GCA 74(14), 3897-3912. 